Canadian

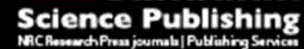

Canadian Journal of Microbiology Revue canadienne de de microbiologie

\title{
A Diaminopimelic Acid Auxotrophic Escherichia coli Donor Provides Improved Counterselection Following Intergeneric Conjugation with Actinomycetes
}

\begin{tabular}{|r|l|}
\hline Journal: & Canadian Journal of Microbiology \\
\hline Manuscript ID: & cjm-2015-0041.R3 \\
\hline Manuscript Type: & Article \\
\hline Complete List of Authors: & $\begin{array}{l}\text { Allard, Nancy; Université de Sherbrooke, Biologie } \\
\text { Garneau, Daniel; Université de Sherbrooke, Biologie } \\
\text { Poulin-Laprade, Dominic; Université de Sherbrooke, Biologie } \\
\text { Burrus, Vincent; Université de Sherbrooke, Biologie } \\
\text { Brzezinski, Ryszard; Université de Sherbrooke, Biologie } \\
\text { Roy, Sebastien; Université de Sherbrooke, Biologie }\end{array}$ \\
\hline Keyword: & $\begin{array}{l}\text { Intergeneric conjugation, counterselection, diaminopimelic acid, } \\
\text { actinomycetes }\end{array}$ \\
\hline
\end{tabular}


1 A Diaminopimelic Acid Auxotrophic Escherichia coli Donor Provides Improved

2 Counterselection Following Intergeneric Conjugation with Actinomycetes

4 Nancy Allard, Daniel Garneau, Dominic Poulin-Laprade, Vincent Burrus, Ryszard 5 Brzezinski, Sébastien Roy*

7 Centre d'étude et de valorisation de la diversité microbienne (CEVDM), Département de

8 biologie, Faculté des sciences, Université de Sherbrooke, Sherbrooke (Québec), Canada.

$9 \quad$ Nancy.Allard@USherbrooke.ca, Daniel.Garneau@USherbrooke.ca, Dominic.Poulin-

10 Laprade@USherbrooke.ca, Vincent.Burrus@USherbrooke.ca,

11 Ryszard.Brzezinski@USherbrooke.ca, Sebastien.Roy@USherbrooke.ca.

$13 *$ Corresponding author

14 Département de biologie, Faculté des sciences, Université de Sherbrooke, 2500, boul. de 15 l'Université, Sherbrooke, Qc, J1K 2R1, Canada. Tel : +1 8198218000 extension 62505;

16 Fax: +1 819 8218049; E-mail: Sebastien.Roy@USherbrooke.ca

\section{Abstract}

18 Considering the medical, biotechnological, and economical importance of actinobacteria,

19 there is a continuous need to improve the tools for genetic engineering of a broad range

20 of these microorganisms. Intergeneric conjugation has proven to be a valuable yet

21 imperfect tool for this purpose. The natural resistance of many actinomycetes against

22 nalidixic acid (Nal) is generally exploited to eliminate the sensitive Escherichia coli

23 donor strain following conjugation. Nevertheless, Nal can delay growth and have other 
24 unexpected effects on the recipient strain. To provide an improved alternative to

25 antibiotics, we propose a post-conjugational counterselection using a diaminopimelic acid

26 (DAP) auxotrophic donor strain. The DAP-negative phenotype was obtained by

27 introducing a dapA-deletion into the popular methylase-negative donor strain

28 ET12567/pUZ8002. The viability of ET12567 and its $\triangle d a p A$ mutant exposed to DAP

29 deprivation or Nal selection were compared in liquid pure culture and after mating with

30 Streptomyces coelicolor. Results showed that death of the E. coli $\triangle$ dapA Nal-sensitive

31 donor strain occurred more efficiently when subjected to DAP deprivation than when

32 exposed to Nal. Our study shows that post-conjugational counterselection based on DAP

33 deprivation circumvents the use of antibiotic and will facilitate the transfer of plasmids

34 into actinomycetes with high biotechnological potential, yet currently not accessible to 35 conjugative techniques.

\section{$37 \quad$ Key words}

38 intergeneric conjugation, counterselection, diaminopimelic acid, actinomycetes.

\section{Résumé}

41 Étant donné l'importance médicale, biotechnologique et économique des actinobactéries,

42 il y a un besoin constant d'améliorer les outils permettant de modifier génétiquement un 43 large éventail de ces microorganismes. La conjugaison intergénérique est un outil 44 éprouvé pourtant imparfait à cet effet. La résistance naturelle de plusieurs actinomycètes 45 à l'acide nalidixique (Nal) est généralement exploitée pour éliminer la souche donneuse 46 d'Escherichia coli sensible, à la suite d'une conjugaison. Toutefois, le Nal peut affecter la 
47 croissance et avoir des effets inattendus sur la souche réceptrice. Pour offrir une

48 alternative à l'antibiotique $\mathrm{Nal}$, nous proposons une technique de contre-sélection en

49 utilisant une souche donneuse auxotrophe pour l'acide diaminopimélique (DAP). Le

50 phénotype DAP-negatif a été obtenu en introduisant la délétion de dapA chez la populaire

51 souche donneuse méthylase-négative ET12567/pUZ8002. La viabilité d'ET12567 et de

52 son mutant $\triangle d a p A$, exposé soit à la sélection par carence en DAP ou par sensibilité au

53 Nal, ont été comparées en culture pure liquide et après une conjugaison avec

54 Streptomyces coelicolor. Les résultats démontrent que la mortalité chez E. coli $\Delta$ dapA

55 sensible au Nal se produit plus efficacement en absence de DAP qu'en présence de Nal.

56 Notre étude démontre que cette méthode de contre-sélection post-conjugationnelle

57 permet d'éviter l'utilisation d'antibiotique et facilitera le transfert de plasmides chez des

58 actinomycètes ayant un potentiel biotechnologique, pour lesquels les techniques de

59 conjugaison ne sont pas encore accessibles.

60

61 Mots clés

62 conjugaison intergénérique, contre-sélection, acide diaminopimélique, actinomycètes.

\section{Introduction}

64 The actinomycetes comprise a diverse group of Gram-positive, filamentous bacteria 65 renowned for being the most important producers of antibiotics and other secondary 66 metabolites such as immunosuppressants, antitumor compounds, antivirals, and 67 antiparasitic agents (Bibb 2013). These commercially valuable compounds are largely 68 used in agriculture, food production and pharmacology. Consequently, there is a constant 69 need to develop new approaches for the genetic manipulation of a wide range of 
70 industrially relevant actinomycetes. Genetic tools are crucial for the identification and

71 functional analysis of biosynthetic pathways involved in metabolite production, the

72 optimization of the expression of genes of interest, as well as the engineering of

73 overproducing strains (Baltz 2011).

74

75 Bacterial conjugation has proven to be a valuable tool, given the large amount of genetic

76 material that can be transferred per conjugation event and the broad host range of some

77 conjugative plasmids. Intergeneric conjugation between Escherichia coli and a variety of

78 Gram-positive bacteria was initially demonstrated by (Trieu-Cuot et al. 1987).

79 Afterwards, (Mazodier et al. 1989) developed the first protocol for conjugation between

80 E. coli and Streptomyces. Ever since, conjugative transfer of plasmids has often been

81 used efficiently to introduce foreign DNA into multiple actinobacterial genera such as

82 Corynebacterium (Schäfer et al. 1990), Saccharopolyspora (Matsushima et al. 1994),

83 Actinomaduras, Arthrobacter, Micromonospora, Nocardia, Rhodococcus (Voeykova et

84 al. 1998), Amycolatopsis (Stegmann et al. 2001), Nonomuraea (Stinchi et al. 2003), and

85 Actinoplanes (Heinzelmann et al. 2003). Unfortunately, despite the progress made in

86 these conjugation-based methodologies, several inherent limitations remain, including the

87 ability to counterselect the exconjugants against the donor strain. The natural resistance

88 of many actinobacteria to nalidixic acid ( $\mathrm{Nal}$ ) is generally exploited to eliminate the

89 sensitive E. coli donor strain following conjugation. Nevertheless, to circumvent the use

90 of antibiotics, which could have unexpected effects on the recipient strain, we exploited

91 an alternative counterselection approach. 
93 In E. coli, the first enzyme of the diaminopimelate pathway is dihydrodipicolinate 94 synthetase (DHDPS) encoded by the dapA gene (Richaud et al. 1986). This enzyme is 95 required for the biosynthesis of D,L-diaminopimelic acid (meso-DAP), which provides 96 the cross-linkage of peptidoglycan in many Gram-negative and mycobacterial cell walls.

97 Furthermore, DAP serves as a direct precursor of lysine, one of the 20 essential amino 98 acids. Previous work showed that disruption of this metabolic pathway leads to bacterial 99 cell death and renders E. coli unable to grow in media lacking DAP (Born and Blanchard 100 1999). The successful use of auxotrophic donors to facilitate the selection of 101 exconjugants has been exploited in conjugations with Bartonella (Dehio and Meyer 1997, 102 Dehio et al. 1998), Vibrio (Demarre et al. 2005), Burkholderia (López et al. 2009), and 103 Pseudomonas (Thoma and Schobert 2009). However, these auxotroph strains are DNA 104 methylation proficient, which is inappropriate for conjugation with actinomycete methyl105 restricting hosts, since even hemi-methylated DNA represents a barrier to the 106 introduction of heterologous DNA (Flett et al. 1997). Therefore, we constructed a $\triangle d a p A$ 107 mutant of the methylation-deficient E. coli ET12567 to achieved counterselection easily, 108 without affecting the recipient strains by the addition of antibiotic following conjugation.

\section{Materials and methods}

\section{Bacterial strains and culture conditions}

111 Methylation-deficient E. coli ET12567 (dam-13::Tn9, dcm-6, hsdM, hsdS) was used as 112 recipient for transduction of the $\triangle d a p A$ mutation and as the donor strain in intergeneric 113 mating experiments. ET12567 harbors the non-transmissible helper plasmid pUZ8002, a 114 derivative of RK2 able to mobilize other plasmids efficiently (MacNeil et al. 1992). 115 Routinely, E. coli ET12567 was grown at $37^{\circ} \mathrm{C}$ in LB medium, with shaking (225 rpm) 
116 or on LB agar. Streptomyces coelicolor A3(2) M145 (SPC1-, SPC2) was cultured at 30

$117{ }^{\circ} \mathrm{C}$ on SLM3 agar (DeWitt 1985) for the preparation of spore stocks, which were 118 subsequently stored in $20 \%$ glycerol at $-20{ }^{\circ} \mathrm{C}$. Mannitol soya flour (MS) medium (Kieser 119 et al. 2000) was used for the mating assays and subsequent selection of exconjugants and 120 total count of recipients. Exconjugants chosen for further analysis were spread onto 121 tryptic soy agar (TSA) containing apramycin (selectable marker carried by the 122 mobilizable plasmid pSET152) and then, grown at $30{ }^{\circ} \mathrm{C}$ with shaking $(225 \mathrm{rpm})$ in 123 tryptic soy broth (TSB). To allow growth, culture media for E. coli ET12567 $\triangle$ dapA were 124 supplemented with $0.3 \mathrm{mM}$ DL- $\alpha, \varepsilon$-diaminopimelic acid (DAP). DAP was also added to 125 growth medium in some control experiments with the wild-type ET12567 strain. When 126 required, the antibiotics were used at the following concentrations: $50 \mu \mathrm{g} / \mathrm{ml}$ apramycin 127 sulfate (Apr), $25 \mu \mathrm{g} / \mathrm{ml}$ chloramphenicol (Cam), $200 \mu \mathrm{g} / \mathrm{ml}$ erythromycin (Erm), 25-50 $128 \mu \mathrm{g} / \mathrm{ml}$ kanamycin sulfate (Kan), $25 \mu \mathrm{g} / \mathrm{ml}$ nalidixic acid sodium salt (Nal). 129

\section{Transduction}

133 The deletion of the dapA gene in E. coli ET12567/pUZ8002 was introduced by P1vir 134 transduction using DPL12 (E. coli MG1655 $\Delta$ dapA::(erm-pir)) (Carraro et al. 2014) as 135 donor. The latter strain bears a 185-bp deletion within the reading frame of the dapA gene 136 (Richaud et al. 1993) further disrupted by a synthetic erm-pir operon (Demarre et al. 137 2005). Transductants were recovered after $24 \mathrm{~h}$ of growth on LB agar containing Kan (25 $138 \mu \mathrm{g} / \mathrm{ml})$, Cam and Erm to select for $\mathrm{pUZ8002,} \mathrm{the} \mathrm{dam} \mathrm{mutation} \mathrm{and} \mathrm{the} \triangle$ dapA mutation, 
139 respectively. DAP was also added to the medium to allow growth of the $\triangle d a p A$ strains. 140 DAP-deficient mutants were tested for the lethal phenotype in the absence of 141 exogenously added DAP. The deletion of dapA in two mutants was further confirmed by 142 PCR analysis using primers flanking the deletion region (Fig. S1). The amplification and 143 sequencing of a 1820-bp fragment of the rpoD gene, encoding the RNA polymerase 144 primary $\sigma^{70}$ factor was used as a PCR positive control (Fig. S1).

\section{Growth curves}

147 The growth characteristics of E. coli strains were compared in LB medium supplemented 148 or not with various combinations of DAP or Nal. The strains were initially grown in $5 \mathrm{ml}$ 149 LB medium (supplemented with DAP for the $\triangle d a p A$ mutant) for $18 \mathrm{~h}$, then washed twice 150 in LB medium and brought to equal cell densities $\left(\mathrm{OD}_{600 \mathrm{~nm}}\right.$ of 0.1$)$ in $50 \mathrm{ml}$ of fresh $\mathrm{LB}$ 151 medium with appropriate supplements. Growth was monitored for $22 \mathrm{~h} 35$ (1355 min) at $15237{ }^{\circ} \mathrm{C}$ with continuous shaking (225 rpm). Each condition was tested in three biological 153 replicates and the growth curves were based on duplicate measures of $\mathrm{OD}_{600 \mathrm{~nm}}$ for each 154 sample. The ability to grow into colony forming units (CFUs) was estimated by serial 155 dilutions of several time points of the growth curve culture, and plating on LB agar 156 (supplemented with DAP for the $\triangle d a p A$ mutant). The count of CFUs was used to 157 determined the mean \% of survival (Survival $(\%)=$ number of CFUs at time X / number 158 of CFUs at time $0 \times 100)$. 159

160 Fluorescence microscopy 
161 To estimate the cell wall integrity, E. coli cells were collected at three time points during 162 growth $(0,210$, and $390 \mathrm{~min})$ and stained for $15 \mathrm{~min}$ in the dark at room temperature with

163 LIVE/DEAD ${ }^{\circledR}$ BacLight Bacterial Viability Kit (Invitrogen, Carlsbad, USA) according to 164 the manufacturer's instructions. The two nucleic acid stains were used as a 1:1 mixture of 165 the green fluorescent SYTO 9 and the red fluorescent propidium iodide (PI). When 166 appropriate, samples were diluted $1: 10$ or 1:100 in LB medium prior to the staining 167 procedure to allow cell counting by fluorescence microscopy. A volume of $20 \mu \mathrm{l}$ of the 168 stained bacterial suspension was trapped between a slide and a $20 \times 30 \mathrm{~mm}$ cover glass. 169 Pictures were taken after $20 \mathrm{~min}$ to allow the deposition of the cells. Images were 170 acquired on an Axio Imager M1 (Zeiss) using a 40X objective and appropriate excitation 171 and emission filters for each fluorescent dye. Experimental error was reduced with the 172 acquisition of eight images (random fields) per slide per dye $(n=3)$. Image pre-processing 173 and segmentation were performed with CellProfiler software version 2.1 (Carpenter et al. 174 2006). Threshold was applied to identify PI positive cells and the percentage of positive 175 cells per image was determined. For each condition, the mean and standard error of the 176 mean (SEM) were calculated.

\section{Intergeneric conjugation}

179 E. coli ET12567 (pUZ8002/pSET152) or its $\triangle$ dapA mutant were used as donors in 180 intergeneric conjugations. The model actinomycete Streptomyces coelicolor A3(2) M145 181 was selected as recipient since it is a well characterized strain often used in standard 182 experiments (Blaesing et al. 2005). The established protocol for conjugation (Kieser et al. 183 2000) was adapted with the following modifications. The pSET152 vector (Apr ${ }^{\mathrm{R}}$ ) 
184 (Bierman et al. 1992) was used to direct its site-specific integration into the bacteriophage $185 \varphi \mathrm{C} 31$ attachment site in the chromosome of $S$. coelicolor. Approximately $10^{8}$ 186 Streptomyces spores were suspended in $500 \mu \mathrm{l}$ of $2 \times \mathrm{YT}$ broth, heat shocked at $50{ }^{\circ} \mathrm{C}$ for $18710 \mathrm{~min}$ and cooled to room temperature. The spore suspensions were spread onto a 188 polycarbonate membrane filter (PCTE, $0.2 \mu \mathrm{M}, 25 \mathrm{~mm}$, Main manufacturing, MI, USA), 189 placed onto MS agar with $10 \mathrm{mM} \mathrm{MgCl}_{2}$, supplemented or not with $0.3 \mathrm{mM}$ DAP. The 190 plates were incubated $30 \mathrm{~min}$ at $30{ }^{\circ} \mathrm{C}$ to allow spore germination. Then a drop of 191 overnight cultures containing $\sim 5 \times 10^{7}$ cells of donor strain was added to the germinated 192 spores and mating was performed at $30{ }^{\circ} \mathrm{C}$ for 5 or $20 \mathrm{~h}$. Total donor CFUs were 193 quantified at the beginning of the mating by plating appropriate serial dilutions on LB 194 agar \pm DAP. Mating partners were recovered in $1 \mathrm{ml}$ of $2 \times Y T$ broth and $100 \mu 1$ of serial 195 dilutions were plated onto selective media to quantify the recipient and exconjugant 196 CFUs. Counterselection of ET12567 strain was carried out by using $25 \mu \mathrm{g} / \mathrm{ml}$ Nal, while 197 counterselection of the $\triangle d a p A$ mutant was achieved by adding either (i) $25 \mu \mathrm{g} / \mathrm{ml} \mathrm{Nal}$ 198 with $0.3 \mathrm{mM}$ DAP or (ii) without Nal nor DAP. The plates were incubated for $18-20 \mathrm{~h}$ 199 and then overlaid with $2.5 \mathrm{ml}$ soft nutrient agar with or without Apr for exconjugants 200 selection and total count of recipient CFUs, respectively. Incubation was continued 3 to 5 201 days until CFUs of exconjugants appeared. To estimate the frequency of spontaneous 202 Apr-resistant mutants, control conjugation mixes were processed as above but with the 203 addition of E. coli donor cells not carrying pSET152. The frequency of exconjugant 204 formation was obtained by dividing the number of exconjugant CFUs by the number of 205 donor CFUs. Exconjugants were further cultured on selective TSA and analyzed by PCR 206 for site-specific integration of pSET152 into the $\varphi \mathrm{C} 31$ attB site. 


\section{Comparison of DAP and Nal counterselection}

209 In order to compare the efficiency of both counterselection approaches, the viability of

210 ET12567 and its $\triangle d a p A$ mutant donor strains was estimated over time following a $5 \mathrm{~h}$

211 mating procedure. To do this, mating partners were resuspended from the membrane

212 filter in $1 \mathrm{ml} 2 \times \mathrm{YT}$ broth and $100 \mu \mathrm{l}$ samples were plated in triplicate onto MS medium 213 supplemented or not with DAP, and DAP + Nal for the $\triangle d a p A$ mutant or onto MS 214 medium with or without Nal for ET12567. The plates were incubated at $30{ }^{\circ} \mathrm{C}$ and the 215 viability of $E$. coli was monitored at $0,2,4$, and $6 \mathrm{~h}$ after conjugation by harvesting the 216 cells from the plates. For this purpose, plates were washed twice with $5 \mathrm{ml} \mathrm{LB}$ medium 217 and gently scraped with a polypropylene cell spreader to retrieve cells. After 218 centrifugation at $500 \mathrm{~g}$ for 10 minutes and removal of the supernatant, the cells were 219 resuspended in $1 \mathrm{ml}$ of LB medium. Serial dilutions were plated on LB agar 220 supplemented with Kan (antibiotic marker carried by pUZ8002) and with or without DAP 221 to allow the growth of the donor strain only. CFUs were counted after $18 \mathrm{~h}$ of incubation 222 at $37^{\circ} \mathrm{C}$. Four replicates were performed for each viability count assay.

\section{DNA isolation and molecular techniques}

225 Preparation and transformation of competent E. coli cells were performed as described by 226 Sambrook and Russell (2001). Streptomyces genomic DNA was isolated using the salting 227 out procedure (Kieser et al. 2000), while E. coli genomic DNA was isolated as described 228 by Rasmussen et al. (2008). PCRs were used to detect the presence of the rpoD and dapA 229 genes in $E$. coli as well as the $\operatorname{acc}(3) I V$ gene segment $\left(\mathrm{Apr}^{\mathrm{R}}\right)$ and the fragments 
230 confirming the site-specific integration of pSET152 in S. coelicolor exconjugants (attR,

$231 a t t L)$. PCRs were carried out in total reaction volumes of $50 \mu 1$ with Easy-A High Fidelity

232 Taq polymerase (Stratagene-Agilent Tech., Mississauga, ON, Canada) according to the

233 manufacturer's instructions. The PCR cycles comprized pre-incubation of 2 min at $95{ }^{\circ} \mathrm{C}$

234 followed by 30 cycles of $40 \mathrm{sec}$ at $95{ }^{\circ} \mathrm{C}, 30 \mathrm{sec}$ at $50-65{ }^{\circ} \mathrm{C}$ (depending on primers

235 used), and $1 \mathrm{~min}$ at $72{ }^{\circ} \mathrm{C}$ with a final extension step of $7 \mathrm{~min}$ at $72{ }^{\circ} \mathrm{C}$. All

236 oligonucleotides (Table 1) were provided by Integrated DNA Technologies (Coralville,

237 IA, USA). When needed, PCR products were purified using the QIAquick gel extraction

238 kit (QIAGEN, Mississauga, ON, Canada) or cloned into pCR2.1TOPO (Invitrogen,

239 Carlsbad, USA) according to the manufacturer's instructions. Sequencing of PCR

240 products was performed at Genome Quebec Innovation Center of McGill University

241 (Montreal, QC, Canada). The DNA sequences were compared with the GenBank DNA

242 sequence database using the BLASTN program (Altschul et al. 1990).

\section{Results}

245 Viability of E. coli ET12567 and its $\Delta$ dapA mutant in pure liquid culture

246 In order to compare the efficiency of the DAP and Nal selections, three approaches were 247 assessed with pure cultures of E. coli ET12567 and its $\triangle$ dapA mutant: cell density in LB 248 medium, CFU counts on LB agar, and verification of the membrane integrity using the 249 SYTO 9 and PI dyes. The growth characteristics of E. coli ET12567 and its $\triangle$ dapA 250 mutant were compared at several time points after either addition of Nal (+ DAP) or the 251 DAP deprivation treatments. The growth of E. coli ET12567 does not seem to be 252 influenced by the presence or absence of exogenously supplied DAP, since the growth 
253 rates remained the same in both conditions (Fig. 1A) even when the cells were treated 254 with $\mathrm{Nal}$ (data not shown). As expected, the growth of the $\triangle$ dapA mutant was completely 255 abolished in LB devoid of DAP, while its growth rate was almost restored to wild-type 256 level when the medium was supplemented with DAP. In the case of selection by Nal 257 sensitivity, the cell densities of ET12567 and its $\triangle$ dapA mutant both remained very low 258 and relatively stable over time (Fig. 1A), but the viable count decreased after 75 min (Fig. 259 1B). Nevertheless, when cultures were further incubated for $22 \mathrm{~h} 35$, cell density slightly 260 increased in the media containing $\mathrm{Nal}\left(\mathrm{OD}_{600 \mathrm{~nm}} 0.37 \pm 0.007\right.$ for $\Delta d a p A$ and $0.94 \pm 0.19$ 261 for ET12567), indicating that some cells were still alive and were beginning to 262 proliferate. It was not the case in the medium lacking DAP, where the $\triangle$ dapA mutant 263 viability sharply declined over time (about a tenfold decrease between each time point in 264 Fig. 1B), suggesting that bacteria underwent cell lysis in the absence of DAP. The results 265 demonstrate that the decrease of cell viability caused by Nal occurred much later and less 266 efficiently than in conditions of DAP deprivation. Those results are also supported by the 267 proportion of survival (Table 2), where the $\triangle$ dapA mutant showed a viability of $6.2 \pm$ $2681.5 \%$ in LB medium supplemented with DAP + Nal, and only $0.1 \pm 0.007 \%$ in DAP-free 269 medium after $210 \mathrm{~min}$ of culture. In the conditions used in our assays, taking advantage 270 of DAP auxotrophy instead of Nal sensitivity is more efficient at stopping cell 271 proliferation, supporting that the use of auxotrophic donors is a more effective 272 counterselection approach.

273

274 To support the effects of DAP deprivation and Nal sensitivity on cell density and CFUs 275 counts, the membrane integrity of E. coli ET12567 and its $\triangle d a p A$ mutant was assessed 
276 using the LIVE/DEAD ${ }^{\circledR}$ BacLight Bacterial Viability Kit. Although the staining method

277 employed cannot prove viability (Netuschil et al. 2014), stained cells are referred to as

278 live or dead cells and the relative proportions are reported in Fig. 1C. Live/Dead ratios of

279 cells harvested at 0, 210, and 390 min (Fig. S2) were achieved on the basis of red-

280 fluorescent PI staining, since this dye penetrates only cells with damaged membrane as

281 opposed to SYTO 9, a green-fluorescent dye that stains all the cells. In LB medium

282 without selection agents, the proportion of live cells in the population of ET12567 strain

283 was stable across the three time points tested $(89.6 \pm 6.2 \%$ of green-only labeled cells).

284 The percentage of live $\triangle d a p A$ mutant treated with Nal in the presence of DAP decreased

285 to $65 \%$ after $210 \mathrm{~min}$. A similar decrease was observed as early as time point 0 min for

286 the $\triangle d a p A$ mutant cultivated in DAP-less medium. At this time point, the cells were

287 observed after about 40 minutes from sampling - the period of time necessary for

288 staining and microphotography. This suggested that deprivation of DAP led to cell death

289 within a very short period of time. Once more, the results demonstrate that the mortality

290 rate occured faster when cells were deprived of DAP than when treated with Nal.

291 Although these observations are consistent with our previous results, it is not known

292 whether the staining of either of the dyes could be distorted, irrespectively of the live or

293 dead status of the cell, given that the $\triangle d a p A$ mutation could have altered the cell wall.

\section{Evaluation of E. coli ET12567 and its $\Delta d a p A$ mutant post-conjugative viability}

296 In order to quantify viability of ET12567 and its $\triangle$ dapA mutant following a mating

297 procedure of $5 \mathrm{~h}$, a CFUs counting approach was used. The $\%$ of survival of $E$. coli were

298 quantified after 0,2 , 4, and 6 h post-conjugation on MS medium with or without DAP, or 
299 in the presence of Nal (+ DAP for the $\triangle d a p A$ mutant). As expected, the addition of DAP 300 allowed exponential growth of the $\triangle d a p A$ mutant over time, which was comparable to the 301 ET12567 strain in absence of selection (Fig. 2). When Nal was also added to the medium, 302 the survival of the $\triangle d a p A$ mutant was substantially reduced after the first $2 \mathrm{~h}$ post303 conjugation $(25.7 \pm 2.6 \%)$, but the mortality rate slowed down during further incubation 304 (Fig. 2). Results obtained with the ET12567 strain were comparable to those of the $305 \triangle d a p A$ mutant, demonstrating that the latter strain does not respond differently to Nal 306 treatment compared to the wild type strain. On the other hand, DAP deprivation 307 following conjugation greatly reduced the survival of the $\Delta d a p A$ mutant after $2 \mathrm{~h}$ of 308 incubation $(13.5 \pm 6.1 \%)$, while there were less than $1.3 \pm 0.4 \%$ of alive cells after $6 \mathrm{~h}$. 309 Consequently, death due to lack of DAP occurred significantly faster than that caused by 310 nalidixic acid sensitivity.

\section{DAP counterselection is suitable for intergeneric conjugation}

313 Mating experiments were carried out using either Nal sensitivity or DAP auxotrophy 314 counterselection against E. coli $\triangle d a p A$ mutant. Following a 5-h mating procedure, the 315 frequency of exconjugant formation was about 3.5 times higher for cells plated on MS 316 containing DAP and Nal compared to DAP-less plates. Extension of the mating contact, 317 to up to $20 \mathrm{~h}$, resulted in increased frequencies of exconjugant formation for both 318 selection approach. Also, when the conjugation period was long-lasting, the difference 319 between the two counterselection techniques became no longer significant (Fig. 3A). 320 Nonetheless, since some streptomycete mycelia started to sporulate on the filter, the 321 exconjugant frequency cannot be used to compare the differences between the two 
322 counterselection techniques. Exconjugant frequencies obtained with the ET12567 strain

323 were similar to those of the $\triangle d a p A$ mutant when sensitivity to Nal was used for

324 counterselection. In all the conditions used, no $\mathrm{Apr}^{\mathrm{R}}$ CFUs were observed in control

325 matings between $S$. coelicolor and E. coli ET12567/pUZ8002 ( $\triangle$ dapA) without the 326 mobilizable plasmid pSET152.

328 Exconjugants were further cultivated on selective TSA plates to confirm the conjugative 329 transfer and stable maintenance of pSET152. Transfer and subsequent integration of 330 pSET152 into the chromosome of $S$. coelicolor was confirmed in all five exconjugants 331 examined by PCR amplification of the Apr resistance gene fragment and the right and left 332 attachment sites (attR, attL) of $\varphi \mathrm{C} 31$ (Fig. 3B). While recovery of a few E. coli CFUs 333 was sporadically observed on plates with Nal selection, it was not the case when using 334 DAP deprivation. To evaluate the possible persistence of E. coli cells when cultivating 335 recipients strains, exconjugants were transferred in selective TSB with simultaneous Nal 336 selection or in the presence of DAP. After retrieving total genomic DNA, PCR 337 amplification of the E. coli rpoD gene was performed, but rpoD fragment could not be 338 detected in any of the conditions (data not shown).

340 Discussion

341 Bacterial conjugation is one of the most popular methods used to introduce DNA into 342 actinomycetes (Flett et al. 1997). Here, we propose a post-conjugation counterselection 343 based on DAP deprivation rather than antibiotic selection. This study is the first 344 systematic comparison of two different strategies to eliminate the E. coli donor following 
345 an intergeneric mating procedure with actinobacteria. While antibiotics, such as 346 phosphomycin (Blaesing et al. 2005), and gentamycin (Li et al. 2003), have been used for

347 counterselection following intergeneric conjugation, nalidixic acid is the most commonly 348 used with actinomycete recipient strains. This quinolone antibiotic inhibits DNA gyrase, 349 an enzyme important for maintaining the topology of genome and essential for 350 chromosomes condensation and partitioning at cell division (Champoux 2001), resulting 351 in DNA synthesis inhibition and bacterial death. Our results revealed that Nal is less 352 efficient than DAP deprivation for selecting against $E$. coli cells in the conditions of our 353 mating experiment. Previous studies showed that selectable phenotypic variations exist in 354 isogenic populations, without significant genotypic variation, allowing a fraction of the 355 cells to survive antibiotic selection, while most died (Adam et al. 2008, Sánchez-Romero 356 and Casadesús 2014). Moreover, the mutation rate for a single gene occur at 357 approximately $2 \times 10^{-7}$ or $3 \times 10^{-9}$ per division in different E. coli K-12 strains (Drake 358 1991). Even if the rate at which antibiotic resistance can arise is much lower, there are 359 preexisting spontaneous Nal-resistant mutants in a population. Both these phenomena 360 could explain the increased optical density of the cultures with Nal selection after $22 \mathrm{~h} 35$ 361 of growth (Fig. 1A), as well as the appearance of E. coli CFUs on selective MS medium 362 following counterselection with Nal after a mating procedure. Therefore, our results 363 suggest that phenotypic heterogeneity of bacterial population limits the effectiveness of 364 Nal counterselection against $E$. coli donors.

366 An easy way to circumvent the use of nalidixic acid is to use an auxotrophic donor strain.

367 Many type of auxotrophies exist but most of them are alleviated by compounds found in 
368 rich media (Demarre et al. 2005). Only a few auxotrophies can be counterselected on rich 369 complex media, such as mutants requiring 5-aminolevulinic acid (Thoma and Schobert 370 2009) or diaminopimelic acid (Demarre et al. 2005) for growth. DAP auxotrophs are 371 well-characterized and have been used for different purposes for many years. In E. coli, 372 genes involved in the DAP metabolic pathway have been inactivated, such as dapA, $B, C$, 373 D, E (Bukhari and Taylor 1971, Dehio et al. 1997, Dehio et al. 1998). Other genes have 374 been targeted in other strains: asd in Salmonella (Curtiss et al. 1989, Galán et al. 1990), 375 Neisseria (Hatten et al. 1993), and Shigella (Sizemore et al. 1995), ask in Mycobacterium 376 (Pavelka et al. 1996), dapB in Pseudomonas (Rediers et al. 2003), asd and dapB in 377 Burkholderia (Norris et al. 2009), dapA in Yersinia (Bland et al. 2011). All such mutants 378 are unable to grow on media without DAP supplementation. The use of a $\triangle d a p A$ mutant 379 is suitable for counterselection, given that the bacterial growth is inhibited by two 380 mechanisms. First, meso-DAP is a major constituent of peptidoglycan, acting as a cross381 linking agent in the bacterial cell wall. Its absence directly compromises cellular 382 integrity. Second, DAP serves as a direct precursor of lysine thus, leading to the inability 383 of a $\triangle d a p A$ mutant to synthesize proteins (Pavelka and Jacobs 1996). It is possible that a 384 fraction of the bacterial population could act as 'scavengers' and uptake the peptidoglycan 385 components released from neighbouring cells which underwent lysis. However, it does 386 not seem to be the case, probably because of the cumulative effects of DAP deprivation 387 on protein synthesis inhibition. Thereby, the absence of DHDPS enzyme confers an 388 absolute dependence on exogenous DAP for viability and growth. Unlike Nal, for which 389 some natural resistance could be seen, no spontaneous reversion of the DAP-dependent 390 growth is possible. Therefore, DAP auxotrophy is a more convenient and effective 
391 counterselection approach given that it can be easily done on commonly used media, as

392 they are based on yeast or animal extracts which lack DAP (Demarre et al. 2005). Also,

393 the selection of exconjugants can be obtained under optimal growth conditions in 394 significantly shorter time (Thoma and Schobert 2009), which is especially interesting for 395 slow-growing bacteria.

397 When comparing both counterselection approaches following a 5-h mating procedure, it 398 seems that using Nal selection is favorable since the exconjugant frequency was about 3.5 399 times higher than in the condition of DAP deprivation. Those results were unusual since 400 previous investigations have demonstrated that the addition of Nal to mating pairs of 401 sensitive donor and resistant recipient in liquid resulted in an immediate arrest of 402 conjugative plasmid transfer in E. coli (Barbour 1967, Bouck and Adelberg 1970, Hane 403 1971). However, in order to perform selection after intergeneric conjugation, cells were 404 plated on solid medium rather than being in a liquid mixture. Thus the entry of Nal in the 405 cells could be less efficient or delayed, allowing some donor cells to reinitiate 406 conjugative transfer of DNA. It is also possible that the actual concentration of Nal on 407 plates was lower than expected due to the soybean component in MS agar known to 408 absorb some antibiotics (Thamchaipenet et al. 2013). Therefore, Nal is less efficient than 409 DAP deprivation to kill $E$. coli cells in the context of a mating experiment. Still, for 410 actinobacteria which generally present low exconjugant frequencies, a long-lasting 411 mating procedure can be appropriate to benefit from the DAP counterselection technique.

412 To further modify our current donor strain, one could consider introducing a recA 413 mutation to avoid fortuitous recombination between the helper plasmid pUZ8002 and the 
414 plasmid that is meant to be mobilized, and/or integrating pUZ8002 into the donor 415 genome.

417 In this work, we demonstrate the usefulness of a $\triangle d a p A$ mutant as an alternative to 418 antibiotic counterselection in bacterial intergeneric conjugation. This counterselection 419 approach makes conjugation accessible to a wider range of bacterial species potentially 420 sensitive to Nal, like Micromonospora sp. 40027 (Li et al. 2003), avoiding the need to 421 screen for a Nal resistant recipient. Even if the procedures need customization for 422 individual species before achieving acceptable efficiencies, conjugation with 423 actinomycetes is simpler than DNA transformation methods, which require the 424 production and regeneration of protoplasts. Moreover, E. coli is host to models of genetic 425 regulation and is compatible with an evergrowing number of tools for genetic 426 engineering. Therefore, other existing popular E. coli donor strains, such as S17-1 or

427 SM10 could be modified by introducing the dapA mutation and inactivating further DNA 428 methylation systems. Given that most seldom-studied or newly discovered actinobacterial 429 strains lack adequate genetic tools, the use of a DAP-auxotroph E. coli donor is of 430 interest to facilitate and accelerate molecular genetic studies on the highly heterogenous 431 actinobacteria of ecological and industrial interest.

\section{Acknowledgements}

434 This work was financially supported by a Team Research Project grant from the FQRNT 435 (Fonds québécois de la recherche sur la nature et les technologies) to R. B., V. B. and S. 436 R.. N. A. and D. P.-L. were recipients of a doctoral fellowship from the FQRNT. 


\section{$438 \quad$ References}

439 Adam, M., Murali, B., Glenn, N.O., and Potter, S.S. 2008. Epigenetic inheritance based 440 evolution of antibiotic resistance in bacteria. BMC Evolutionary Biology. 8 : 52. doi: 10.1186/1471-2148-8-52.

442 Altschul, S.F., Gish, W., Miller, W., Myers, E.W., and Lipman, D.J. 1990. Basic local 443 alignment search tool. J. Mol. Biol. 215 : 403-410.

Baltz, R.H. 2011. Strain improvement in actinomycetes in the postgenomic era. J. Ind. Microbiol. Biotechnol. 38 : 657-666. doi: 10.1007/s10295-010-0934-z.

Barbour, S.D. 1967. Effect of nalidixic acid on conjugational transfer and expression of episomal Lac genes in Escherichia coli K12. J. Mol. Biol. 28 : 373-376.

Bibb, M.J. 2013. Understanding and manipulating antibiotic production in actinomycetes. Biochem. Soc. Trans. 41(6) : 1355-1364. doi: 10.1042/BST20130214.

450

Bierman, M., Logan, R., O'Brien, K., Seno, E.T., Rao, R.N., and Schoner, B.E. 1992. Plasmid cloning vectors for the conjugal transfer of DNA from Escherichia coli to Streptomyces spp.. Gene. $116: 43-49$.

Blaesing, F., Mühlenweg, A., Vierling, S., Ziegelin, G., Pelzer, S., and Lanka, E. 2005. Introduction of DNA into Actinomycetes by bacterial conjugation from E. coliAn evaluation of various transfer systems. J. Biotechnol. 120 : 146-161.

Bland, D.M., Eisele, N.A., Keleher, L.L., Anderson, P.E., and Anderson, D.M. 2011. Novel genetic tools for diaminopimelic acid selection in virulence studies of Yersinia pestis. PLoS ONE. 6(3) : e17352. doi:10.1371/journal.pone.0017352. 
459 Born, T.L., and Blanchard, J.S. 1999. Structure/function studies on enzymes in the

460

461

462

463

464

465

466

467

468

469

470

471

472

473

474

475

476

477

478

479

480

481 diaminopimelate pathway of bacterial cell wall biosynthesis. Curr. Opin. Chem.

Biol. 3 : 607-613.

Bouck, N., and Adelberg E.A. 1970. Mechanism of action of nalidixic acid on conjugating bacteria. J. Bacteriol. 102(3) : 688-701.

Bukhari, A.I., and Taylor, A.L. 1971. Genetic analysis of diaminopimelic acid- and lysine-requiring mutants of Escherichia coli. J. Bacteriol. 105(3) : 844-854.

Carpenter, A.E., Jones, T.R., Lamprecht, M.R., Clarke, C., Kang, I.H., Friman, et al. 2006. CellProfiler: image analysis software for identifying and quantifying cell phenotypes. Genome Biol. 7 : R100. doi:10.1186/gb-2006-7-10-r100.

Carraro, N., Sauvé, M., Matteau, D., Lauzon, G., Rodrigue, S., and Burrus, V. 2014. Development of pVCR94 $\mathrm{XX}$ from Vibrio cholerae, a prototype for studying multidrug resistant IncA/C conjugative plasmids. Front. Microbiol. 5 : 44. doi: 10.3389/fmicb.2014.00044.

Champoux, J.J. 2001. DNA topoisomerases: structure, function, and mechanism. Annu. Rev. Biochem. 70 : 369-413.

Curtiss, R. III, Nakayama, K., and Kelly, S.M. 1989. Recombinant avirulent Salmonella vaccine strains with stable maintenance and high level expression of cloned genes in vivo. Immunol. Invest. 18 : 583-596.

Dehio, C., and Meyer, M. 1997. Maintenance of broad-host-range incompatibility group $\mathrm{P}$ and group $\mathrm{Q}$ plasmids and transposition of Tn5 in Bartonella henselae following conjugal plasmid transfer from Escherichia coli. J. Bacteriol. 179(2) : $538-540$. 
482 Dehio, M., Knorre, A., Lanz, C., and Dehio, C. 1998. Construction of versatile high-level

483

484

485

486

487

488

489

490

491

492

493

494

495

496

497

498

499

500

501

502

503

504 expression vectors for Bartonella henselae and the use of green fluorescent protein as a new expression marker. Gene. $215: 223-229$.

Demarre, G., Guérout, A.-M., Matsumoto-Mashimo, C., Rowe-Magnus, D.A., Marlière, P., and Mazel, D. 2005. A new family of mobilizable suicide plasmids based on broad host range R388 plasmid (IncW) and RP4 plasmid ( IncP $\alpha$ ) conjugative machineries and their cognate Escherichia coli host strains. Res. Microbiol. 156 : $245-255$.

DeWitt, J.P. 1985. Evidence for a sex factor in Streptomyces erythreus. J. Bacteriol. 164(2) : 969-971.

Drake, J.W. 1991. Spontaneous mutation. Annu. Rev. Genet. 25 : 125-146.

Flett, F., Mersinias, V., and Smith, C.P. 1997. High efficiency intergeneric conjugal transfer of plasmid DNA from Escherichia coli to methyl DNA-restricting streptomycetes. FEMS Microbiol. Lett. 155 : 223-229.

Galán J.E., Nakayama, K., and Curtiss, R. III. 1990. Cloning and characterization of the asd gene of Salmonella typhimurium: use in stable maintenance of recombinant plasmids in Salmonella vaccine strains. Gene. 94 : 29-35.

Hane, M.W. 1971. Some effects of nalidixic acid on conjugation in Escherichia coli K12. J. Bacteriol. 105(1) : 46-56.

Hatten L.-A., Schweizer, H.P., Averill, N., Wang, L., and Schryvers, A.B. 1993. Cloning and characterization of the Neisseria meningitidis asd gene. Gene. 129 : 123-128.

Heinzelmann, E., Berger, S., Puk, O., Reichenstein, B., Wohlleben, W., and Schwartz, D. 2003. A glutamate mutase is involved in the biosynthesis of the lipopeptide 
antibiotic friulimicin in Actinoplanes friuliensis. Antimicrob. Agents Chemother. 47(2) : 447-457.

Kieser, T., Bibb, M.J., Buttner, M.J., Chater, K.F., and Hopwood, D.A. 2000. Practical Streptomyces Genetics. Norwich, UK: The John Innes Foundation.

Li, X., Zhou, X., and Deng, Z. 2003. Vector systems allowing efficient autonomous or integrative gene cloning in Micromonospora sp. strain 40027. Appl. Environ. Microbiol. 69(6) : 3144-3151.

López, C.M., Rholl, D.A., Trunck, L.A., and Schweizer, H.P. 2009. Versatile dualtechnology system for markerless allele replacement in Burkholderia pseudomallei. Appl. Environ. Microbiol. 75(20) : 6496-6503.

MacNeil, D.J., Gewain, K.M., Ruby, C.L., Dezeny, G., Gibbons, P.H., and MacNeil, T. 1992. Analysis of Streptomyces avermitilis genes required for avermectin biosynthesis utilizing a novel integration vector. Gene. 111 : 61-68.

Matsushima, P., Broughton, M.C., Turner, J.R., and Baltz, R.H. 1994. Conjugal transfer of cosmid DNA from Escherichia coli to Saccharopolyspora spinosa: effects of chromosomal insertions on macrolide A83543 production. Gene. 146 : 39-45.

521 Mazodier, P., Petter, R., and Thompson, C. 1989. Intergeneric conjugation between Escherichia coli and Streptomyces species. J. Bacteriol. 171(6) : 3583-3585.

523 Netuschil, L., Auschill, T.M., Sculean, A., and Arweiler, N.B. 2014. Confusion over live/dead stainings for the detection of vital microorganisms in oral biofilms which stain is suitable? BMC Oral Health. 14 : 2. doi:10.1186/1472-6831-14-2.

526 Norris, M.H., Kang, Y., Lu, D., Wilcox, B.A., and Hoang, T.T. 2009. Glyphosate resistance as a novel select-agent-compliant, non-antibiotic-selectable marker in 
chromosomal mutagenesis of the essential genes asd and dapB of Burkholderia pseudomallei. Appl. Environ. Microbiol. 75(19) : 6062-6075. doi:10.1128/AEM.00820-09.

Pavelka, M.S., Jr and Jacobs, W.R., Jr 1996. Biosynthesis of diaminopimelate, the precursor of lysine and a component of peptidoglycan, is an essential function of Mycobacterium smegmatis. J. Bacteriol. 178(22) : 6496-6507.

Rasmussen, L.D., Zawadsky, C., Binnerup, S.J., Øregaard, G., Sørensen, S.J., and Kroer, N. 2008. Cultivation of hard-to-culture subsurface mercury-resistant bacteria and discovery of new merA gene sequences. Appl. Environ. Microbiol. 74(12) : 37953803. doi:10.1128/AEM.00049-08.

Rediers, H., Bonnecarrère, V., Rainey, P.B., Hamonts, K., Vanderleyden, J., and De Mot, R. 2003. Development and application of a dapB-based in vivo expression technology system to study colonization of rice by the endophytic nitrogen-fixing bacterium Pseudomonas stutzeri A15. Appl. Environ. Microbiol. 69(11) : 68646874. doi:10.1128/AEM.69.11.6864-6874.2003.

Richaud, C., Mengin-Lecreulx, D., Pochet, S., Johnson, E.J., Cohen, G.N., and Marlière, P. 1993. Directed evolution of biosynthetic pathways. Recruitment of cysteine thioethers for constructing the cell wall of Escherichia coli. J. Biol. Chem. 268(36) : 26827-26835.

Richaud, F., Richaud, C., Ratet, P., and Patte, J.-C. 1986. Chromosomal location and nucleotide sequence of the Escherichia coli dapA gene. J. Bacteriol. 166(1) : 297300. 
550 Sambrook, J., and Russell, D.W. 2001. Molecular cloning: a laboratory manual, $3^{\text {rd }}$ ed. 551 Cold Spring Harbor Laboratory Press, Cold Spring Harbor, NY.

552 Sánchez-Romero, M.A., and Casadesús, J. 2014. Contribution of phenotypic 553 heterogeneity to adaptive antibiotic resistance. Proc. Natl. Acad. Sci. USA. 111(1) : 355-360. doi:10.1073/pnas.1316084111.

Schäfer, A., Kalinowski, J., Simon, R., Seep-Feldhaus, A.-H., and Pühler, A. 1990. Highfrequency conjugal plasmid transfer from Gram-negative Escherichia coli to various Gram-positive coryneform bacteria. J. Bacteriol. 172(3) : 1663-1666.

Sizemore, D.R., Branstrom, A.A., and Sadoff, J.C. 1995. Attenuated Shigella as a DNA delivery vehicle for DNA-mediated immunization. Science. 270 : 299-302.

Stegmann, E., Pelzer, S.,Wilken, K., and Wohlleben,W. 2001. Development of three different gene cloning systems for genetic investigation of the new species Amycolatopsis japonicum MG417-CF17, the ethylenediaminedisuccinic acid producer. J. Biotechnol. 92 : 195-204.

Stinchi, S., Azimonti, S., Donadio, S., and Sosio, M. 2003. A gene transfer system for the glycopeptide producer Nonomuraea sp. ATCC39727. FEMS Microbiol. Lett.

567 Thamchaipenet, A., Bunyoo, C., Jaemsaeng, R., Lohmaneeratana, K., Rungin, S., and Phornphisutthimas, S. 2013. Intergeneric conjugation: A practical method for genetic manipulation in actinomycetes. In Molecular Biology of Bacteria. Nova Science Publishers. New York. USA p. 1-18.

571 Thoma, S., and Schobert, M. 2009. An improved Escherichia coli donor strain for 572 diparental mating. FEMS Microbiol. Lett. 294 : 127-132. 
573 Trieu-Cuot, P., Carlier, C., Martin, P., and Courvalin, P. 1987. Plasmid transfer by 574 conjugation from Escherichia coli to Gram-positive bacteria. FEMS Microbiol. $575 \quad$ Lett. $48: 289-294$.

576 Voeykova, T., Emelyanova, L., Tabakov, V., and Mkrtumyan, N. 1998. Transfer of 577 plasmid pTO1 from Escherichia coli to various representatives of the order 578 Actinomycetales by intergeneric conjugation. FEMS Microbiol. Lett. 162 : 47-52.

579 
580 Figure legends

581 Fig. 1. DAP deprivation is more efficient than Nal sensitivity to reduce E. coli viability. 582 A) Growth curves at $37{ }^{\circ} \mathrm{C}$ of $E$. coli ET12567 and its $\triangle$ dapA mutant in $50 \mathrm{ml}$ LB 583 medium supplemented as indicated. The growth was estimated by optical density 584 measurements $\left(\mathrm{OD}_{600 \mathrm{~nm}}\right)$. Data points are the means and SEM of three independent 585 experiments. B) Quantification of the CFUs corresponding to various time points 586 assessed in A. At each time point, $10 \mu 1$ of serial dilutions of cultures were plated on LB 587 agar \pm DAP and incubated at $37^{\circ} \mathrm{C}$ for $18 \mathrm{~h}$. C) Estimation of the membrane integrity of 588 E. coli ET12567 and its $\triangle$ dapA mutant at three time points assessed in A, using 589 propidium iodide staining and fluorescence microscopy. The results are the mean and 590 SEM of three independent experiments with 8 images per experiment per dye at each 591 time point.

592

593 Fig. 2. Assessment of the survival of E. coli ET12567 and its $\Delta d a p A$ mutant following 5-

$594 \mathrm{~h}$ mating assays and counterselection using either DAP deprivation or Nal sensitivity. 595 Mating partners were retrieved from the mating filters and plated on medium 596 supplemented as indicated. Cells were retrieved after 0, 2, 4, and $6 \mathrm{~h}$ of incubation at 30 $597{ }^{\circ} \mathrm{C}$ and CFUs were enumerated by plating the appropriate dilutions on LB agar + Kan \pm 598 DAP to counterselect the recipient strain. For each condition, the \% of survival was 599 determined by dividing the CFUs at 2, 4, and $6 \mathrm{~h}$ by the CFUs at $0 \mathrm{~h}$, an estimation of the 600 E. coli population right after conjugation. Results are the mean and SEM of four 601 independent experiments. 
603 Fig. 3. DAP counterselection is suitable for intergeneric conjugation. A) Conjugative 604 transfer of pSET152 from E. coli ET12567/pUZ8002 and its $\triangle$ dapA mutant to $S$. 605 coelicolor A3(2) M145 in mating assays of 5 or $20 \mathrm{~h}$. The mating partners were plated on 606 mannitol soya flour (MS) medium containing appropriate supplements for 607 counterselection. The frequency of exconjugants formation was calculated by dividing 608 the exconjugants CFUs $\left(\mathrm{Apr}^{\mathrm{R}}\right)$ by the donors CFUs $\left(\operatorname{Kan}^{\mathrm{R}}\right)$. For all the mating assays, the 609 donor E. coli ET12567/pUZ8002 ( $\triangle$ dapA) lacking pSET152 was used as a negative 610 control resulting in no $\mathrm{Apr}^{\mathrm{R}}$ CFUs for all conditions. Results are the mean and SEM of 611 four independent experiments. Statistical analyses were performed using the two-tailed 612 Student's $t$-test to compare both counterselection techniques. B) Verification of the 613 integration of pSET152 into the chromosome of $S$. coelicolor exconjugants selected in 5$614 \mathrm{~h}$ mating assays in A. Amplification of the transferred vector's selection marker (acc(3)IV 615 gene segment, $202 \mathrm{bp})$ and its chromosomal attachment sites (attR, $513 \mathrm{bp}$, and attL, 517 616 bp). Lanes: 1, E. coli ET12567/pSET152 $\Delta$ dapA; 2, S. coelicolor A3(2) M145; 3-7, S. 617 coelicolor A3(2) M145/pSET152. 
1 Table 1. Primers used in this study

\begin{tabular}{llll}
\hline Primer & Nucleotide sequence & Target & Fragment size (bp) \\
\hline rpoDEcoli-F & 5'-ATGGAGCAAAACCCGCAGTCAC-3' & rpoD E.coli & 1820 \\
rpoDEcoli-R & 5'-AGCACTTCAGAACGGCTCGG-3' & & \\
dapA-F & 5'-ATGTTCACGGGAAGTATTGT-3' & dapA E. coli & 879 \\
dapA-R & 5'-TTACAGCAAACCGGCAT-3' & \\
Apr-F & 5'-GTTCATGTGCAGCTCCATCAGCAA-3' & acc(3)IV gene & 202 \\
Apr-R & 5'-ACGCTACGGAAGGAGCTGTG-3' & fragment & \\
Sco4178441-F & 5'-CTGGACGCTGCCACTGCGGA-3' & attR & \\
pSET-R & 5'-GCCCGGCGCTTCGCTGAAAT-3' & & \\
pSET-F & 5'-TCCAGACGTCCCGAAGGCGT-3' & attL \\
Sco4179035-R & 5'-GAGGGAATGACCTCCGGGCT-3' & & \\
& & & \\
\end{tabular}


4 Table 2. Time-course assay of cell viability.

\begin{tabular}{lcc}
\hline Strain (medium) & \multicolumn{2}{c}{ Survival $(\%)$} \\
& $\mathrm{t}=210 \mathrm{~min}$ & $\mathrm{t}=390 \mathrm{~min}$ \\
\hline ET12567 (LB) & $1768 \pm 229$ & $10376 \pm 305$ \\
ET12567 (LB + Nal) & $5.9 \pm 0.6$ & $1.7 \pm 0.4$ \\
$\triangle d a p A(\mathrm{LB}+\mathrm{DAP}+\mathrm{Nal})$ & $6.2 \pm 1.5$ & $1.1 \pm 0.05$ \\
$\triangle \operatorname{dap} A(\mathrm{LB})$ & $0.04 \pm 0.007$ & $0.004 \pm 0.0004$
\end{tabular}

5 Note: Viability was estimated as \% of survival on LB agar supplemented or not with DAP,

6 obtained by dividing the number of CFUs at time 210 or $390 \mathrm{~min}$ by the number of CFUs

7 at time 0 during the growth curves assessed in Fig. 1A.

8 


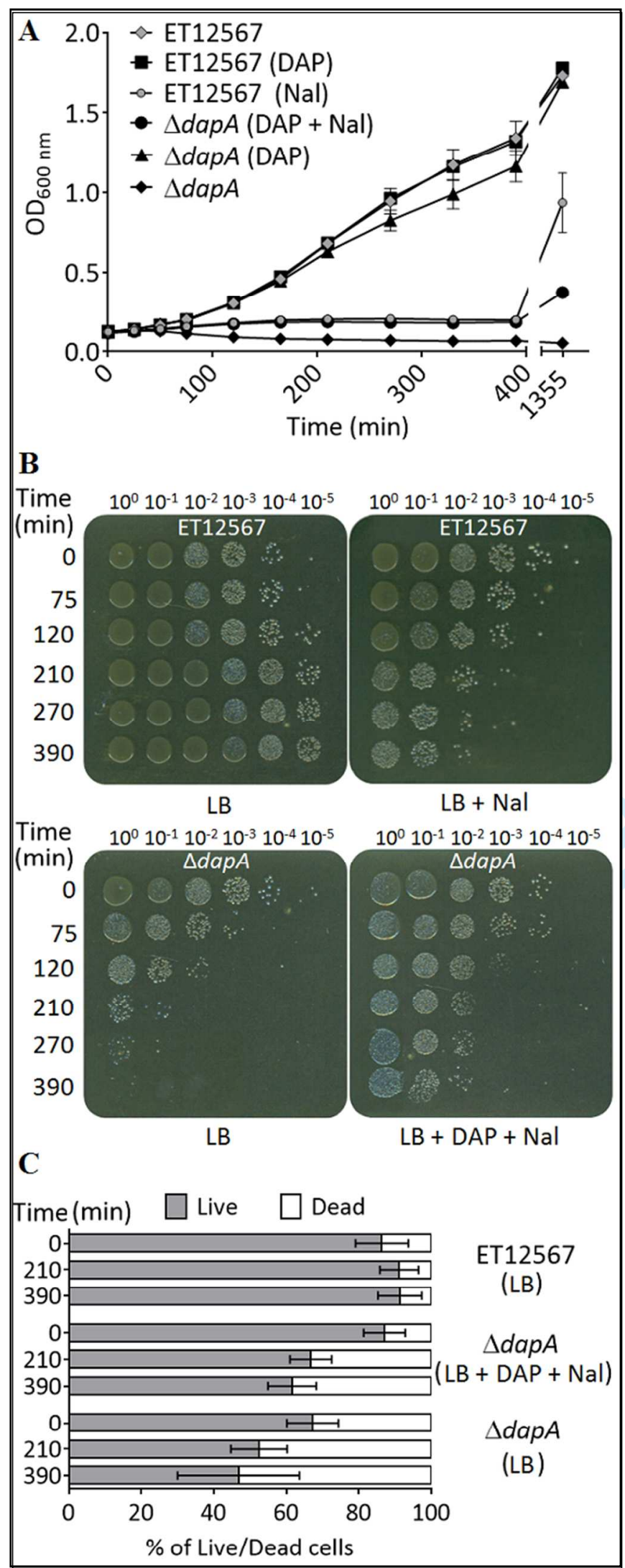


Fig. 1. DAP deprivation is more efficient than Nal sensitivity to reduce $E$. coli viability. 


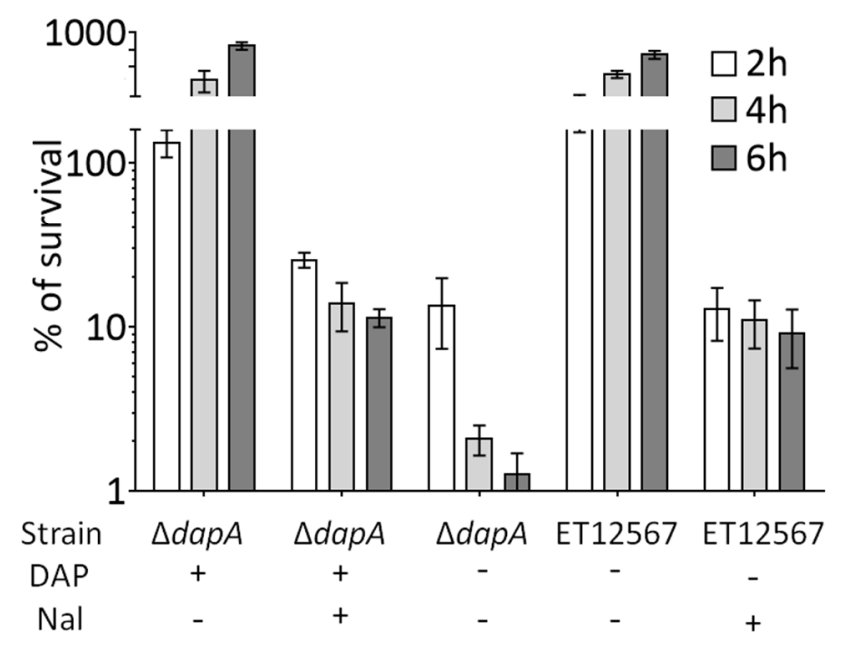

Fig. 2. Assessment of the survival of E. coli ET12567 and its $\triangle d a p A$ mutant following 5h mating assays and counterselection using either DAP deprivation or Nal sensitivity. 


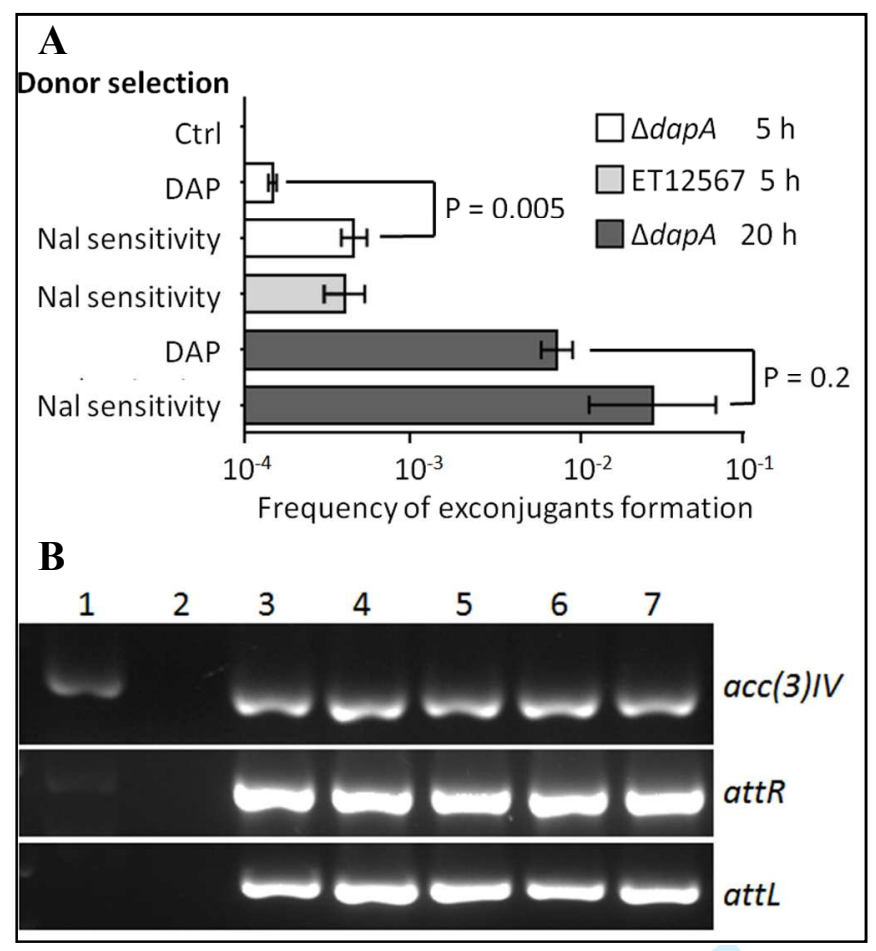

1 Fig. 3. DAP counterselection is suitable for intergeneric conjugation. 